\title{
INSTITUCIONALIZAÇÃO E LIMITES DA AVALIAÇÃO POR PARES NO CNPQ
}

(1951-2015)

\author{
Anderson Cleiton Fernandes Leite* \\ Ivan Rocha Neto ${ }^{* *}$
}

Resumo: O presente artigo tem como objetivo a descrição histórica da avaliação por pares no Conselho Nacional de Desenvolvimento Científico e Tecnológico (CNPq). Metodologicamente aliou-se um levantamento quantitativo das bolsas implementadas anualmente pelo órgão durante o período que vai de 1951 até 2015 com uma análise documental do corpus normativo do CNPq. As fontes primárias foram os dados disponibilizados pelo Centro de Memória do CNPq assim como o conjunto de Resoluções Normativas relacionadas à Avaliação por Pares elaborados pelo Conselho durante o citado período. O referencial teórico que fundamentou tal análise centrou-se nos conceitos de Campo Científico de Pierre Bourdieu e Reconhecimento de Axel Honneth. Como resultado, concluise que o crescimento no número de bolsas assim como o das normas ligadas a Avaliação por Pares acabou por provocar o abandono de critérios vagos e pessoais como "reputação" típicos da esfera dos afetos, nos termos de Honneth - dando lugar a gradual ampliação de normas mais minuciosas e formais que regulam desde a escrita dos pareceres até o comportamento dos avaliadores.

Palavras-chave: Avaliação por Pares. CNPq. Campo Científico. Reconhecimento.

\section{Introdução}

O objetivo desse trabalho é analisar os processos de avaliação por pares no Conselho Nacional de Desenvolvimento Científico e Tecnológico (CNPq) durante os anos de 1951 a 2015, tendo como referencial teórico os conceitos de Campo Científico de Pierre Bourdieu e Reconhecimento de Axel Honneth. Segundo o sociólogo francês, o campo científico:

\footnotetext{
é o lugar, o espaço de jogo de uma luta concorrencial. O que está em jogo especificamente nessa luta é o monopólio da autoridade científica definida, de maneira inseparável, como capacidade técnica e poder social; ou, se quisermos, o monopólio da competência científica, compreendida enquanto capacidade de falar e de agir legitimamente (isto é, de maneira autorizada e com autoridade), que é socialmente outorgada a um agente determinado (BOURDIEU, 1983, p. 122, grifos do autor).
}

\footnotetext{
* Doutor em Educação em Ciências pela Universidade Federal do Rio Grande do Sul - UFRGS.

${ }^{* *} \mathrm{PhD}$ em Eletrônica - pela University of Kent (Inglaterra).
} 
O bem a ser acumulado neste "jogo" pelos integrantes do campo científico seria o a "competência científica" que é "socialmente outorgada", em um processo no qual um grupo concede ao vencedor uma espécie de autoridade legitimada. O cientista oferece aos outros pares-concorrentes novas informações, dados e interpretações para deles receber em troca o reconhecimento (BOURDIEU, 2008, p. 78). Em outro trecho, a ligação entre capital científico e reconhecimento é reforçada: “o capital científico é uma espécie particular de capital simbólico, capital fundado no conhecimento e no reconhecimento" (BOURDIEU, 2008, p. 53).

O reconhecimento tem sido uma categoria que atraiu o interesse de um sem número de filósofos, psicanalistas e sociólogos desde, pelo menos, Hegel. Axel Honneth a partir de Luta por reconhecimento de 1992 (HONNETH, 2009), defende que para além do âmbito individual e psicológico, a sociedade moderna pode ser interpretada como uma arena na qual se estabeleceu uma permanente luta por reconhecimento. Luta essa que não visa a destruição do outro, pois sem esse outro chega-se ao ponto no qual os envolvidos na luta "terão destruído então a fonte do reconhecimento de que precisam para confirmar sua visão de si como pessoas" (SINGER, 2003, p. 84). Para ele, os mais diversos grupos sociais para sobreviverem devem desenvolver a capacidade de influenciar a esfera pública de modo a ter sua concepção de vida reconhecida e poderem adentrar ao sistema de referência moral da comunidade no qual se encontram (HONNETH, 2003, p. 473-478).

Assim, constata-se que a dinâmica do campo científico se fundamenta na busca pelo acúmulo de um bem escasso: o capital científico. Busca essa que estabelece uma luta pelo reconhecimento dos concorrentes. Tal processo se efetiva na prática social com os agentes se avaliando mutuamente em diversos momentos da atividade cientifica - a assim chamada avaliação por pares.

$\mathrm{O}$ artigo prossegue com o estabelecimento de uma conceituação, tipologia e um levantamento de críticas e propostas relativas a avaliação por pares. Segue-se uma reconstrução diacrônica de 1951 até 2015 da prática da avaliação por pares no CNPq que busca articular o crescimento quantitativo da implementação de bolsas no órgão com o corpus normativo que formaliza os modos como o órgão avaliava as propostas de bolsas e projetos durante o citado período. 


\section{Avaliação por pares}

A avaliação por pares pode ser considerada a prática pela qual a qualificação, a legitimidade e a eficácia de um discurso científico é dada por indivíduos ou grupos de semelhantes ao próprio emissor do discurso, os chamados pares, o que acaba fazendo dela "o sistema de controle de qualidade científica” (KERN; SARAIVA; PACHECO. 2003, p. 38).

Para Campanário (2002) o processo de avaliação por pares sustenta-se no tripé paridade, pluralidade e anonimato. O "par" no contexto da ciência é um especialista do mesmo campo de atuação (VELHO, 2016). Mais que individual, a avaliação deve ser feita por mais de um par, de modo a dirimir idiossincrasias pessoais e permitir que vários olhares de especialistas possam emitir um julgamento mais confiável do texto. E, por fim, o anonimato do autor e do árbitro garantiria uma maior independência na análise a ser efetuada.

Apesar de suas raízes no século XVII, a avaliação por pares nos termos atuais, surge após a Segunda Guerra Mundial (ROWLAND, 2002, p. 248). Este período é quando se estabelece, nas palavras de Michael Polanyi (1974), a "República da Ciência" no qual agências de fomento estatais surgem do encontro entre burocratas, representando interesses governamentais, e cientistas buscando recursos para suas pesquisas. Instaura-se um campo de conflitos no qual ministérios, agências de fomento, indústrias, universidades, grupos de pesquisa e cientistas disputam espaço institucional, capacidade decisória e, obviamente, recursos financeiros. (RIP, 1994, p. 3 - 4). Em tal "República" os cientistas ocupavam um lugar de suma importância em função de seu status epistêmico, por assim dizer. Segundo Joelmo de Oliveira (2016, p. 131) “o papel dos cientistas nesse paradigma de política vai além do exercício de autoridade cognitiva; eles atuam como reguladores políticos do processo decisório, definindo tanto a agenda temática de fomento quanto as estratégias de implementação".

\section{Avaliação por pares: tipologia}

Tal contexto fez com que os grupos interessados buscassem elaborar métodos de avaliação das atividades e propostas das áreas de ciência e tecnologia (HOLBROOK, 1992) Estabelecem-se três tipos básicos de avaliação por pares centradas em diferentes etapas da pesquisa, seja ela por fazer (ex ante), já feita (ex post) ou ainda em realização (BORNMANN, 2013, p. 01). 
A avaliação ex ante centra-se no desempenho possível de um projeto ainda não realizado. Nas últimas décadas essa avaliação foi necessariamente incorporada às ferramentas de gestão de políticas públicas na área de C\&T. "Com base nesta premissa, o julgamento por pares tem sido amplamente utilizado pelas agências financiadoras - governamentais, universitárias, e também privadas - para alocar recursos a indivíduos ou grupos que apresentam propostas de pesquisa" (DAVYT; VELHO, 2000, p. 101).

A avaliação ex post trata da "capacidade demonstrada" no qual se analisa o desempenho e os trabalhos já realizados pelo pesquisador avaliado (DAVYT; VELHO, 2000, p. 101). Por fim, torna-se cada vez mais comum avaliação durante a execução da pesquisa, de modo a fornecer um parâmetro para a correção de rumo da mesma, caso necessário.

Quanto a relação entre avaliadores e avaliados, apresentam-se três tipos básicos de avaliação: aberto (open peer review), simples-cego (single-blind) e duplo cego (double-blind). Segundo Trzesniak e Koller (2009, p. 91) "No primeiro caso, os autores sabem quem são as pareceristas e vice-versa. No segundo, os consultores têm conhecimento de quem são os autores, mas não o inverso. No terceiro, o anonimato é mantido para ambas as partes”. Em pesquisa conduzida em 2009 com pesquisadores com "4.037 pesquisadores em todo o mundo com reconhecida atividade como revisores" o sistema simples-cego foi considerado satisfatório por $45 \%$ dos entrevistados, pois eliminaria vieses, encorajaria opiniões honestas e teria como foco a qualidade do manuscrito. Além disso, muitos sustentam que "conhecer o autor é importante para melhor entender o conteúdo do artigo e ajuda a detectar o plagiarismo" (NASSI-CALÒ, 2015).

\section{Limites e críticas aos modelos de avaliação por pares}

Apesar de seu papel como uma das principais ferramentas de controle da dinâmica do campo científico, a avaliação por pares é questionada por muitos integrantes da própria comunidade científica. Benos et al. (2007) elencam pesquisas nos quais deficiências metodológicas e estatísticas intencionalmente introduzidos em manuscritos não foram detectadas pela grande maioria dos pareceristas. Em 2013, biólogo John Bohannon submeteu a diversas revistas versões de um artigo científico fictício, com pequenas diferenças entre si, assinado por um autor inexistente. 157 periódicos aceitaram o trabalho que apresentava uma série de erros conceituais e de interpretação, enquanto 98 o rejeitaram (NASSI-CALÒ, 2016).

Triggle e Triggle (2007) arrolam estudos nas quais informações como laboratório, universidade e nacionalidade do pesquisador interferem no juízo dos pareceristas. 
Levantamentos, como as de Lloyd (1990), detectaram a interferência de viés de gênero na avaliação por pares. Dentre os resultados, os revisores do sexo feminino foram significativamente menos propensas a aceitar a versão masculina do manuscrito (10\%) em comparação com a versão do sexo feminino (62\%) - sendo que em ambos eram os mesmo textos.

Mesmo ideias inovadoras tem sofrido resistência de revisores e editores. Segundo Lee et al. (2013, p. 09), os revisores por vezes padecem de um viés conservador que acaba por rechaçar trabalhos inovadores e fora dos parâmetros aceitos, ainda que sejam cientificamente relevantes. Hans Krebs, que descobriu o ciclo do ácido cítrico, e Barbara McClintock, responsável pela descoberta da transposição genética, foram agraciados com Prêmio Nobel por trabalhos rejeitados anteriormente por uma revista do gabarito da Nature (KILWEIN, 1999).

Segundo Harding (2002) a avaliação por pares nos moldes atuais ainda padece de uma série de pontos cegos, especialmente quanto a detecção de fraudes, tais como: fabricação de dados, falsificação de resultados, plágio e redundância (quando uma mesma investigação gera diferentes artigos sem nenhum tipo de diferença substancial entre eles). Nos últimos anos até mesmo artigos falsos gerados por programas de computação têm passados incólumes a toda a estrutura de avaliação (SPINAK, 2014).

Como resultante de todos esses gargalos e limitações, a própria comunidade científica apresenta uma postura ambígua quanto à eficácia da avaliação por pares. Neste sentido, Kyvik e Langeldt (2011) descrevem como os procedimentos avaliativos entre pares perpassam praticamente todas as esferas da atividade científica: análise de projetos em busca de subvenção, análise de propostas para conferências, avaliação de manuscritos de artigos ou livros, sugestão de candidaturas para prêmios, bancas de mestrado, doutorado ou graduação, resenhas e consultorias científicas para órgãos de fomento. Tal situação acarretaria tensões e conflitos entre a obrigação de avaliar e a própria pesquisa da qual cada cientista se encarrega.

Em contraposição às críticas acima elencadas, especialmente as que acusam a avaliação por pares de não conseguir extirpar aspectos subjetivos e parciais na decisão dos pareceristas, Davyt e Velho (2000) afirmam que tais críticas pressupõem um grau de objetividade e desinteresse humanamente impossíveis, sendo que "estas críticas se centram na ideia do cientista 'neutro', capaz de julgar de forma imparcial com base exclusivamente em seu conhecimento técnico". Problemas como os citados anteriormente na avaliação por pares 
podem ser dirimidos, mas não neutralizados, pois são intrínsecos à própria estrutura mental humana. Neste diapasão, o psicólogo Sílvio Botomé (2011, p. 338) declara que "O contexto de qualquer avaliação de um trabalho é um conjunto de comportamentos humanos como quaisquer outros, [e] envolve sempre critérios políticos e até pessoais, mesmo que inconscientes por parte de quem realiza a 'avaliação"”.

Campanário (2002) chega a se referir à possibilidade de se abolir definitivamente os revisores, optando por uma total abertura dos manuscritos - via internet, por exemplo - na qual a revisão seria feita pela própria comunidade como um todo. Seria, segundo Lee at al. (2013, p. 11) um a posteriori peer review tal como realizada pela revista canadense Open Medicine. A diferença entre a avaliação por pares tradicional e uma avaliação aberta póspublicação pode ser sintetizada no fato de que na primeira um pequeno grupo julga o artigo, enquanto na segunda potencialmente toda a comunidade interessada pode agregar comentários e críticas (ROWLAND, 2002, p. 254).

\section{A Prática da avaliação por pares no CNPq (1951 - 2015)}

A levar em conta o decreto de regulamentação do CNPq de 1951, não existia uma normatização precisa quanto às condições para a concessão de bolsas ou auxílios ${ }^{1}$. Segundo o decreto, cada um dos setores técnicos do CNPq teria como atribuição "o estudo dos pedidos de auxílios para a realização de cursos, bem como para a concessão de bolsas" (BRASIL, 1951). Para efetuar tal tarefa, o CNPq poderia "requisitar [...] ou contratar pessoal científico e técnico especializado, nacional ou estrangeiro, de comprovada idoneidade, bem como instituir comissões consultivas de homens de ciência pura e aplicada" (BRASIL, 1951). Diante desta ausência de parâmetros detalhados, a avaliação por pares nesta fase da história do CNPq baseava-se "em juízos informais de um grupo limitado de cientistas transformados em administradores, que se valiam, quando necessário, de pareceres de colegas" (CASTRO; SOARES, 1986, p. 166).

\footnotetext{
${ }^{1}$ Um breve excurso metodológico faz-se necessário neste ponto: as fontes primárias privilegiadas no presente artigo foram as Resoluções Normativas (RN) exaradas pela administração do CNPq no período que vai de 1951 a 2015. O recorte de quais seriam os documentos relevantes para a pesquisa acabou por centra-se apenas nas RN relacionadas à avaliação de propostas de bolsas e auxílios assim como aquelas relativas aos Comitês de Assessoramento (CA) e Consultores Ad Hoc. À exceção das RN 04/1975 e 01/1976 - que só puderam ser consultadas in loco no arquivo do Setor de Normas do CNPq - todos outros documentos encontram-se acessíveis on-line na página do Conselho.
} 
A informalidade e a ausência de normalização quanto a avaliação por pares podem ser compreendidas quando relacionada ao relativo baixo índice de bolsas implementadas durante as duas primeiras décadas de funcionamento do órgão.

O campo científico, enquanto sistema de relações objetivas entre posições adquiridas (em lutas anteriores), é o lugar, o espaço de jogo de uma luta concorrencial. O que está em jogo especificamente nessa luta é o monopólio da autoridade científica definida, de maneira inseparável, como capacidade técnica e poder social; ou, se quisermos, o monopólio da competência científica, compreendida enquanto capacidade de falar e de agir legitimamente (isto é, de maneira autorizada e com autoridade), que é socialmente outorgada a um agente determinado (BOURDIEU, 1983, p. 122, grifos do autor)

O gráfico a seguir mostra a quantidade de bolsas-ano ${ }^{2}$ que foram implementadas pelo CNPq em sua primeira década de existência, perfazendo uma média de quase 237 bolsas-ano.

Gráfico 1 - Concessão de Bolsa-Ano 1951-1961.

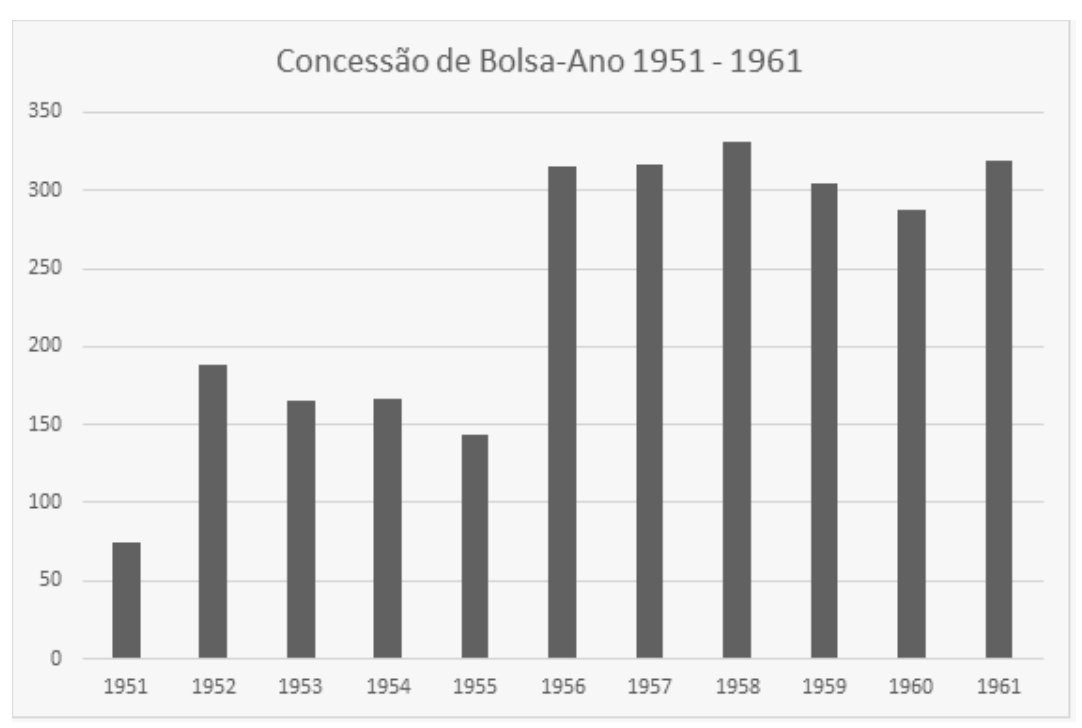

Fonte: Centro de Memória CNPq. ${ }^{3}$

\footnotetext{
${ }^{2}$ Cada bolsa-ano equivale a 12 (doze) mensalidades pagas no ano, podendo corresponder a um ou mais bolsistas não incluindo bolsas de curta duração.

${ }^{3}$ O Centro de Memória do CNPq veicula em seu site (cf. CNPQ, s/d) um levantamento quantitativo das atividade de fomento realizada pelo Conselho com dados para cada ano a partir de 1951. Para cada ano, o site em tela apresenta uma tabela com dados quantitativos no qual se arrolam o total de bolsas-ano implementadas, assim como os valores monetários (não atualizados) investidos no fomento. Com base em tais dados institucionais públicos e consolidados foram elaborados os gráficos que se apresentam no decorrer do artigo.
} 
O gráfico a seguir demonstra o aumento expressivo nas bolsas implementadas pelos CNPq em fins da década de 1960, no qual a média, especialmente em função de um notável crescimento a partir de 1965, chega a 780 bolsas-ano:

Gráfico 2 - Concessão de Bolsas-Ano 1961-1970.

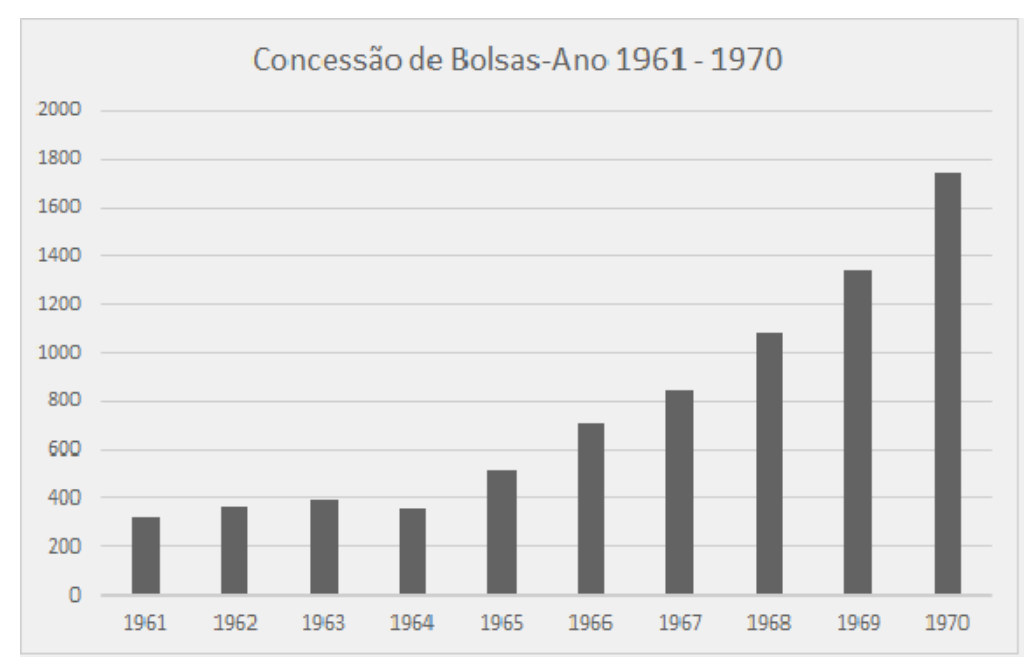

Fonte: Centro de Memória CNPq.

Seguindo a tendência de crescimento das bolsas implementadas que se iniciou na década anterior, constata-se que se fazia necessário a ampliação e efetiva sistematização da avaliação por pares no órgão, especialmente quando se compara a média da década de 1960, de quase 780 bolsas-ano, com a média atingida em apenas 6 anos da década subseqüente: 2823. Não surpreende, então, o crescimento notável que pode ser constatado entre os anos de 1975 e 1976, período da implementação dos CAs, quando se passou de 2930 para 4577 bolsas-ano. Tal incremento na implementação de bolsas é concomitante ao fato de que em 1974, o Governo do Presidente Ernesto Geisel que transforma o "Conselho Nacional de Pesquisas" em "Conselho Nacional de Desenvolvimento Científico" e Tecnológico. Em 1975, a sede do órgão é transferida para Brasília. Com fins de permitir maior agilidade operacional ao CNPq, ele deixa de ser uma autarquia, tornando-se uma fundação de personalidade jurídica de direito privado (CNPq, s/d). 


\section{\#tear}

Gráfico 3 - Concessão de Bolsas-Ano 1970-1976.

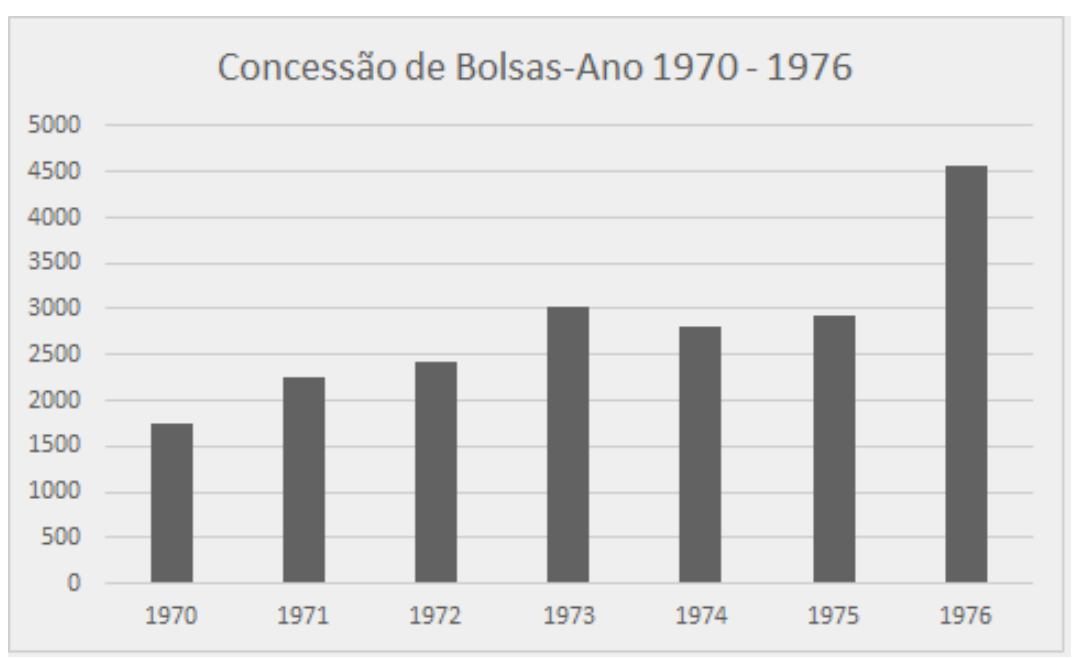

Fonte: Centro de Memória CNPq.

A Resolução Normativa 01/1976 - Comitês Assessores (Especializados em Áreas do Conhecimento) determina a criação e a formalização dos procedimentos dos Comitês Assessores (CA). O caput da norma descreve a necessidade da constituição dos Comitês Assessores em decorrência do recém adquirido papel do Conselho como órgão central do Sistema Nacional de Desenvolvimento Científico e Tecnológico (SNDCT) ${ }^{4}$ que acarretaria "tarefas de coordenação e avaliações contínuas da situação atual e das perspectivas futuras de desenvolvimento da ciência e tecnologia no Brasil" assim como "de um estreito e permanente contato com a comunidade científica e tecnológica, e com as instituições de ensino e pesquisa" (CNPQ, 1976, grifo nosso).

Cada CA teria como propósito dar suporte especializado ao CNPq, sendo que uma de suas principais atribuições seria "Propor a ação fomentadora do CNPq na [sua respectiva] área, inclusive com a apreciação, em calendário e métodos indicados pela Administração do $C N P q$, das solicitações de apoio a pesquisa e à formação de recursos humanos". (CNPQ, 1976, grifo nosso). Destaque-se que os critérios de seleção dos integrantes dos CA ainda não apresentavam nenhum tipo de índice qualitativo ou quantitativo limitando-se a especificar que a escolha deva ser feita dentre os "pesquisadores de reputação, que tenham posição de liderança em sua área e dela possuam conhecimento global” (CNPQ, 1976).

\footnotetext{
4،"Em 1972, o CNPq passou a ser o órgão central do chamado Sistema Nacional de Desenvolvimento Científico e Tecnológico, cujo objetivo era consolidar programas e projetos, bem como incentivar a pesquisa no setor privado e nas chamadas economias mistas. [...] O sistema regido pelo PBDCT (Plano Básico de Desenvolvimento Científico e Tecnológico) é integrado por todas as instituições de pesquisas científicas e tecnológicas, usuárias de recursos governamentais, e foi formalizado em 1975 como Sistema Nacional de Desenvolvimento Científico e Tecnológico - SNDCT. Esse sistema previa a constituição de estruturas setoriais e, posteriormente, expandiu-se para estruturas estaduais" (CNPq, s/d.).
} 
A criação e a natureza dos CA ilustra perfeitamente o que Bourdieu destacou como uma das características essenciais na "luta pela autoridade científica", no caso, o "fato de que os produtores [ou pesquisadores] tendem a só ter como possíveis clientes seus próprios concorrentes" (BOURDIEU, 1983, p. 127).

A escolha dos integrantes dos CA é da alçada exclusiva do Presidente do CNPq a partir da Consultoria Científica. Esta última, constituída em 1975, por meio da Resolução Normativa 04/75, tinha como função "Prestar assistência ao Presidente e Diretoria do CNPq" e, dentre outras atribuições, deveria colaborar "no exame da constituição e composição de Comitês Assessores, e, quando pertinente, na orientação de seus trabalhos". Tal ferramenta institucional seria formada, e aqui a ausência de critério formais de avaliação também se faz presente, "por cientistas, tecnólogos e pesquisadores, de reconhecida reputação, designados pelo Presidente do CNPq" (CNPQ, 1975).

Com a criação em 1985 do Ministério da Ciência e Tecnologia por meio do Decreto $\mathrm{n}^{\circ}$ 91.146 - 15 de Março de 1985 o CNPq perde seu papel de órgão central do sistema federal de Ciência e Tecnologia para o novo Ministério (CNPq, s/d.). Contudo, na segunda metade da década de 1980 houve um forte incremento na quantidade de bolsas implementadas pelo CNPq, o que poderia explicar em parte - assim como na década anterior - esse movimento de expansão da estrutura de avaliação institucional.

Gráfico 4 - Concessão de Bolsas-Ano 1980-1990.

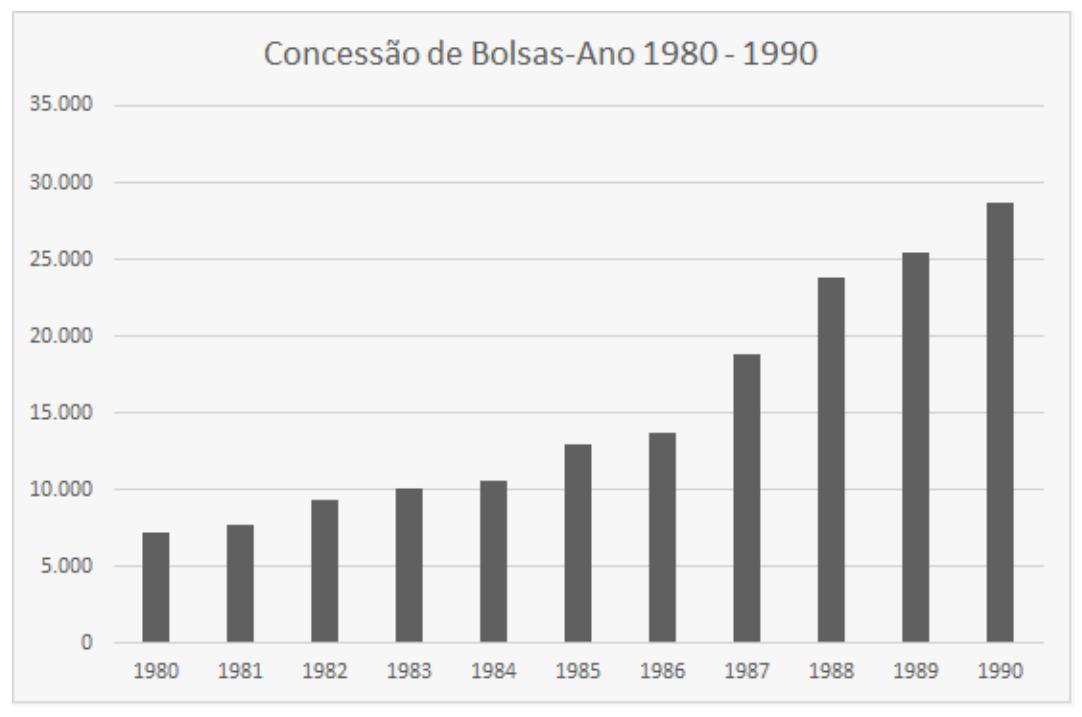

Fonte: Centro de Memória CNPq.

É deste período um outro ponto de inflexão no modo como se praticou a avaliação por pares no CNPq com o surgimento dos Consultores Ad Hoc em 1988. Segundo a Resolução 
Normativa 12/88 (CNPQ, 1988) uma das atribuições dos Consultores Ad Hoc é "Emitir pareceres sobre as solicitações de benefícios, como subsídio às recomendações dos Comitês Assessores ou outros Colegiados com vista à decisão final do Conselho". Mas ao contrário das normas que tratavam dos $\mathrm{CA}$, surge uma série de determinações processuais que delimitam com maior especificidade e clareza os procedimentos a serem adotados no ato de avaliar os projetos apresentados. O parecer do Consultor deve abordar, além do mérito do projeto e do proponente, os seguintes os aspectos: "Qualificação do proponente [...] viabilidade de realização do projeto ou programa relativamente a instituição [...] cronograma previsto e orçamento proposto e estágio e condições do desenvolvimento do projeto ou programa" (CNPq, 1988). Apresentam-se índices qualitativos de avaliação - "mérito", "qualificação", "viabilidade" - e uma determinação quanto à própria escrita dos pareceres que devem ser "claros e explícitos" com a manifestação inequívoca entre recomendar ou não o projeto $(\mathrm{CNPq}, 1988)$.

Outra mudança se dá quanto ao anonimato do avaliador. O CNPq garante, como um dos direitos do consultor ad hoc, que "A identificação dos responsáveis pela emissão dos pareceres 'ad hoc' será preservada pelo CNPq", ou seja, uma avaliação single-blind no qual o proponente não teria ciência de quem é o avaliador da sua proposta. Em contrapartida, tornase explícita a obrigação do consultor ad hoc em guardar sigilo quanto à matéria objeto da avaliação (CNPQ, 1988).

Tal incremento nos dispositivos de regulação e formalização da avaliação por pares também se fez presente na seleção dos consultores ad hoc. Se antes os critérios de seleção dos integrantes dos CAs eram vagos, têm-se no caso dos ad hoc uma série de determinações. Segundo a RN 12/88 (CNPQ, 1988), a seleção ocorre de comum acordo entre o comitê assessor da área e os técnicos do $\mathrm{CNPq}$, o que tira parte do poder de seleção da própria comunidade científica envolvida. E por mais que ainda se leve em conta o critério de "reconhecida competência em sua área de atuação", o artifício em tornar automaticamente todos os bolsistas de pesquisa, nível I, do CNPq em consultores ad hoc - prática que permanece até a atualidade - introduziu uma série de critérios que vão além do nebuloso reconhecimento/reputação por parte dos pares.

Apesar das mudanças iniciadas com o estabelecimento dos consultores ad hoc em 1988, apenas em 1998 a estrutura da avaliação por pares no Conselho apresentou outra alteração substancial. A RN 004/98 rompe com a exclusividade do presidente do CNPq na 
escolha dos integrantes dos CAs e tal função passa para o Conselho Deliberativo(CD) ${ }^{5}$ com "base nos nomes sugeridos pela comunidade científica e tecnológica, segundo critérios estabelecidos pelo CD". Segundo a mesma norma, a indicação de membros dos CAs "será feita a partir de nomes sugeridos pela comunidade científica e tecnológica nacional, segundo critérios e procedimentos a serem fixados no Regimento Interno do CNPq”. Ou seja, o órgão começa a constituir seu corpo de avaliadores com base em uma complexa rede de consultas à própria comunidade científica.

\begin{abstract}
A estrutura da distribuição do capital determina a estrutura do campo, ou seja, as relações de força entre os agentes científicos: a posse de uma quantidade (logo, de uma parte) importante de capital confere poder sobre o campo, portanto, sobre os agentes comparativamente menos dotados de capital (e sobre o requisito de admissão no campo) e comanda a distribuição das hipóteses de lucro (BOURDIEU, 2008, p. 53).
\end{abstract}

Apesar desta série de mudanças no que tange a formação e função dos Comitês, ao contrário dos ad hocs, a atividade dos CAs ainda era marcada pela ausência de determinações formais mais precisas quanto ao julgamento, limitando-se a afirmar que se deve emitir para cada solicitação "parecer conclusivo e fundamentado quanto a seu mérito acadêmico e técnico e à sua adequação orçamentária" (CNPQ, 1998).

Em 2003, com a RN 014/2003, o Conselho Deliberativo, em complementação a regra de escolha dos integrantes dos CAs baseada na consulta a sociedades científicas e tecnológicas das diferentes áreas do conhecimento, escolherá os membros titulares e suplentes dos Comitês entre os pesquisadores bolsistas de Produtividade em Pesquisa de nível 1 ou entre pesquisadores não bolsistas com o perfil de pesquisadores de nível 1 (CNPQ, 2003). Assim como foi feito quanto aos ad hoc em 1988, tal mudança acaba por fornecer uma estrutura legal inexistente até esse momento na seleção dos integrantes dos comitês, dada pela própria norma da Bolsa $\mathrm{PQ}$. Mas não só por ela. Se a norma fornece uma estrutura geral para o acesso a Bolsa PQ, tem-se, a partir de 2003, a determinação de que cada CA estabeleça critérios para a avaliação dos proponentes a Bolsa PQ, levando em conta as especificidades de cada área. Tais critérios deverão obedecer aos seguintes parâmetros: "Esses critérios deverão ser publicados na página do CNPq. Esses critérios poderão ser atualizados uma vez por ano e deverão ter validade para o ano seguinte. Os critérios devem contemplar aspectos quantitativos e qualitativos". (CNPQ, 2003).

\footnotetext{
5 "O Conselho Deliberativo é o órgão superior de fixação da política e de orientação das atividades do CNPq e sua instância máxima de deliberação” (BRASIL, 2002).
} 
Ao selecionar avaliadores dentre os bolsistas de Produtividade, o CNPq acaba por reforçar ainda mais o processo de acúmulo de capital científico em função da própria natureza da bolsa PQ. Segundo Wainer e Vieira (2013, p. 74) um dos fatores mais importantes para ascender ao nível 1 da bolsa PQ encontra-se "a história passada do pesquisador", ou seja, o capital científico acumulado previamente pelo pesquisador: desde a formação escolar até o acesso a cargos administrativos, governamentais, controle sobre institutos de pesquisas, bolsas, consultorias e títulos e distinções (BOURDIEU, 2008, p. 53).

Os critérios, mesmo que levando em conta as especificidades das áreas da alçada de cada CA, devem seguir parâmetros mínimos, tais como: publicidade, obrigatoriedade de mudança periódica e apresentarem aspectos quantitativos e qualitativos em seus itens. A criação dos critérios por área acaba por representar mais um momento de maior formalização e rigor nas esferas de avaliação e reconhecimento entre os pares que se percebe no decorrer da história do CNPq.

A RN 14/2003, trouxe também uma série de restrições quanto a postura e práticas dos integrantes dos comitês. O tom, em geral, tenta prevenir uma série de problemas inerentes à avaliação por pares, como por exemplo, o trecho que veda o integrante de comitê a emitir parecer favorável ou desfavorável motivado por relações pessoais “ou discriminar áreas ou linhas de pensamento [...]comportar-se como representante de uma instituição ou de uma região[...] julgar processos em que tenha interesse pessoal” (CNPq, 2003). No mesmo tom, têm-se uma série de determinações quanto ao comportamento dos próprios integrantes dos CA's de modo a preservar o anonimato e a lisura do próprio julgamento: “é vedado [...] divulgar, antes do anúncio oficial do $\mathrm{CNPq}$, os resultados de qualquer julgamento; [assim como] fazer cópia de processos". Por fim, destaque-se a exigência aberta em se levar em conta os pareceres ad hoc, de modo a garantir que o julgamento de cada proposta apresente uma maior sustentação em diversos pontos de vista, impossibilitando uma decisão monocrática por parte do CA: “é vedado: não levar em conta, sem razão justificada, nas suas recomendações, os pareceres dos assessores ad hoc [assim como] distorcer o conteúdo dos pareceres dos assessores ad hoc" (CNPq, 2003).

Percebe-se que tais determinações vão além da formalização quanto ao tipo de avaliação produzida e foca em aspectos éticos, e portanto, comportamentais dos avaliadores de modo a dirimir a influência de fatores extra científicos em seus pareceres.

Dois anos depois, seguindo ainda a tendência por maior rigor na avaliação por pares, é publicada a RN 017/2005. Para além da genérica determinação de emitir “parecer conclusivo 
e fundamentado quanto a seu mérito acadêmico e técnico e à sua adequação orçamentária" como em 1998, agora se determina que "Os pareceres devem ser claros e consistentes, indicando os motivos da recomendação ou não da concessão de bolsa ou auxílio. [... Em nenhuma hipótese, o Comitê poderá apresentar justificativas que não sejam de mérito na recomendação de concessão ou não de um benefício" (CNPQ, 2005, grifo nosso). Outras mudanças também aparecem na elaboração dos critérios dos CA. Cita-se, pela primeira vez, as subáreas como referência na elaboração dos critérios e, assim como nas recomendações quanto aos pareceres, insiste-se que os "critérios deverão ser formulados de maneira clara e explícita e dizer respeito tão somente ao mérito científico-tecnológico do pesquisador e da solicitação" (CNPQ, 2005, grifo nosso).

Percebe-se que a RN 017/2005 procura fazer com que informações não-relevantes ao mérito científico dos projetos, tais como a instituição a qual se integra o proponente (TRIGGLE; TRIGGLE, 2007), gênero (HARDING, 2000), ou mesmo correntes intelectuais dos autores (ROWLAND, 2002), interfiram no parecer final emitido pelos avaliadores.

$\mathrm{O}$ atual marco legal que estrutura a avaliação por pares no CNPq é a Resolução Normativa 002/2015 (Comitês de Assessoramento, Comitês Temáticos, Núcleos de Assessores em Tecnologia e Inovação, Núcleo de Assessores para Cooperação Internacional e Consultoria Ad Hoc). Segundo ela, os CA “destinam-se a prestar assessoria ao CNPq na formulação de políticas e na avaliação de projetos e programas relativos a sua área de competência, bem como na apreciação das solicitações de bolsas e auxílios (CNPq, 2015a). O Conselho Deliberativo escolhe, ainda, os integrantes dos Comitês entre os pesquisadores bolsistas de Produtividade de categoria I (ou pesquisadores não bolsistas com o perfil de pesquisadores de categoria I). Atualmente, a renovação de membros dos Comitês de Assessoramento (CA) inclui uma consulta por meio eletrônico à comunidade científica nacional, da qual fazem parte pesquisadores nível 1 e sociedades científicas. Mesmo partindo de tal lista, o CD poderá considerar nomes não indicados após a consulta.

Todo o conjunto de competências adquiridas desde 1976 ainda se encontra na referida norma: análise de solicitação de bolsas e auxílios, a obrigação de emitir pareceres claros e consistentes focados no mérito-científico tecnológico, a atuação colegiada - mesmo que em ambiente virtual -, para analisar e avaliar os pareceres dos consultores ad hoc, assim como na elaboração dos critérios públicos referentes às bolsas de Produtividade do CNPq. Permanecem também as vedações quanto a ações que produzam conflito de interesses e que enfraqueçam a lisura processual do julgamento. 


\section{\#tear}

Os pesquisadores bolsistas de Produtividade ainda se integram obrigatoriamente ao quadro de consultores ad hoc do CNPq. Toda uma série de impedimentos ainda permanece, de modo a, assim como no caso dos integrantes dos Comitês, evitarem avaliações enviesadas que coloquem sob suspeição o julgamento de propostas. Destaque-se, por exemplo, o fato de ter "na equipe do projeto cônjuge, companheiro, parente consangüíneo ou afim, em linha reta ou colateral, até o quarto grau, inclusive" como "impedimento para emissão de parecer, assim como ser ou ter sido orientador do solicitante" (CNPq, 2015a). Tais determinações acabam tendo como foco "desvios a favor de, por exemplo, redes elitistas de old boys (cientistas com visões comuns sobre a sua área de pesquisa, colegas ou ainda amigos)" (DAVYT e VELHO, 2000).

A identidade do Consultor ainda é preservada, assim como a exigência de manter a confidencialidade quanto a dados custodiados pelo CNPq a que terá acesso para emissão de parecer de mérito, de modo a "não os utilizar [as informações], individual ou coletivamente, total ou parcialmente, em benefício próprio ou de terceiros, responsabilizando-se por todas as pessoas que vierem a ter acesso às informações por seu intermédio".

\section{Considerações finais}

Para Bourdieu (2004, p. 35) a trajetória de um pesquisador no Campo Científico “está ligada à ocupação de posições importantes nas instituições científicas, [...] e ao poder sobre os meios de produção (contratos, créditos, postos etc.) e de reprodução (poder de nomear e de fazer as carreiras)". Neste sentido, integrar um CA permite ao cientista ter acesso a uma ferramenta privilegiada para um maior acúmulo de capital científico - a avaliação de seus pares. É ela que além de possibilitar a avaliação de concorrentes, permite que o pesquisador influencie as regras de acesso aos recursos, bolsas e cargos do próprio CNPq. O que não é um fato fortuito. Nas palavras de Dagnino (2006, p. 55): "a política de ciência e tecnologia parece ser, em todo o mundo, a política pública mais eficazmente 'capturada' pelo seu ator central - a comunidade de pesquisa" a ponto do ator dominante, a comunidade científica, atuar como se tal política fosse de sua "propriedade". Segundo Baumgarten (2004, p. 40.), tal "captura" se reproduz também no contexto brasileiro, pois "As relações entre Estado e cientistas tiveram, sempre, como espaço privilegiado, as agências de fomento como o CNPq [...]. Dessa forma, planejar e implementar as políticas de C\&T vem sendo uma atividade compartilhada e, por que não dizer, dirigida pelos próprios cientistas". 
Tal fato pode ser constatado ao se analisar as etapas processuais do julgamento de uma proposta de bolsa pelo CNPq. A RN 028/2015 (CNPQ, 2015b), define as seguintes etapas de julgamento: “a) análise pela área técnica; b) análise por consultores ad hoc; c) análise comparativa de mérito e classificação das propostas por Comitês de Assessoramento específicos; e d) decisão final pela Diretoria, em função da disponibilidade financeira do CNPq". Três das quatro etapas do processo são da alçada de membros da própria comunidade científica, inclusive a última de responsabilidade da Diretoria do órgão.

Em contrapartida, tal captura é acompanhada por um crescente rigor legal no decorrer da história do CNPq, no qual se tentou dirimir a interferência de aspectos subjetivos, políticos e particulares na avaliação por pares na instituição. Tal mudança gradativa pode ser compreendida como parte da própria dinâmica moderna do reconhecimento segundo Axel Honneth. Segundo ele, inicialmente as lutas por reconhecimento partem da assim chamada "esfera dos afetos", no qual as relações se fundamentam em laços pessoais e relações primárias entre "poucos indivíduos": parceiros, amigos e familiares (HONNETH, 2009, p. 159 176). No caso da avaliação por pares no CNPq tal esfera compreende as duas primeiras décadas de existência do órgão no qual uma pequena e incipiente comunidade científica tinha como para avaliação de seus pares a reputação e a "posição de liderança" de cada um. (CNPQ, 1976)

Entretanto, o reconhecimento apenas nos termos de relações primárias não é adequado ao espaço público. Neste contexto, a luta por reconhecimento se daria na esfera jurídica de reconhecimento fundada na igualdade legal, proveniente de uma série de leis e regras formalizadas. Os laços pessoais, com suas redes idiossincráticas e mesmo arbitrárias, são dirimidos e mediados via regras gerais e claras baseadas na exigência em reconhecermos "um ser humano como pessoa" em estado de igualdade que garante direitos e evitam exclusões arbitrárias do espaço público (HONNETH, 2009, p.179 - 195). O que fica patente no caso da avaliação por pares no CNPq ao se levar em conta que em 40 anos de mudanças, as normas abandonaram o critério de "reputação" e estabeleceram uma estrutura normativa que regulamenta desde a escrita de pareceres até a postura ética do avaliador integrante do corpo de consultores do Conselho.

Ao se efetuar a reconstrução diacrônica das mudanças no corpus legal referente à avaliação por pares no Conselho, demonstrou-se que ocorreu uma transição da esfera dos afetos para a esfera jurídica. Neste constante processo de tentativa de anulação da informalidade das relações primárias - de resto impossíveis de serem totalmente eliminadas - 
estabeleceu-se um conjunto de regras mais minuciosas e estritas quanto à forma de escrita dos pareceres, ao comportamento dos avaliadores, à publicização dos resultados e, por fim, quanto aos critérios de avaliação institucionais do CNPq.

\section{THE INSTITUTION OF PEER REVIEW IN CNPQ AND ITS LIMITS (1975 - 2015)}

Abstract: This paper analyzes peer review development in CNPq from 1975 to 2015 based on the concepts of theoretical references from Pierre Bourdieu's Scientific Field and Axel Honneth's Recognition. It accomplishes a diachronic reconstruction of peer review practices using as primary source the advisory bodies and committees' and ad hoc consultants' rules. This reconstruction was contextualized using the criteria of the institutional Counsel History and interpreted according to the mentioned theoretical references. I conclude that peer evaluation practices gradually set up Recognition among scientific community members in the sphere of law, reduced informality in primary relations and entailed mediating rules for impersonal relations in Brazilian scientific community.

Keywords: Peer Review. CNPq. Scientific. Field. Recognition.

\section{Referências}

ANDRADE, J. A avaliação por pares. Quím. Nova, São Paulo, v. 28, n. 6, p. 939, Dec. 2005.

BARBIERI, J. C. O Conselho Nacional de Desenvolvimento Científico e Tecnológico. In:

Schwartzman, S. (Coord.). Ciência e tecnologia no Brasil: uma nova política para um mundo global. Brasília: FGV e MCT, 1993.

BAUMGARTEN, M. Comunidades ou coletividades? O fazer científico na era da informação. Revista Crítica de Ciências Sociais, Coimbra, n. 70, p. 33-56, dez. 2004.

BENOS, D. et al. The ups and downs of peer review. Adv Physiol Educ, n. 3, p. 145-152, 2007.

n. 1, p. 1-4, 2013.

BORNMANN, L. Evaluations by Peer Review in Science Springer Science Reviews,

BOTOMÉ, S. Avaliação entre pares na ciência e na academia: aspectos clandestinos de um julgamento nem sempre científico, acadêmico ou de avaliação. Psicologia USP, São Paulo, v. 22, n. 2, p. 335-356, junho 2011. ISSN 1678-5177. Disponível em:

<http://www.revistas.usp.br/psicousp/article/view/42087> Acesso em: 02 aug. 2016.

BOURDIEU, P. O campo científico In: ORTIZ, Renato (org.). Pierre Bourdieu. Sociologia. São Paulo: Ática, 1983.

Os usos sociais da ciência: por uma sociologia clínica do campo científico. São Paulo, Editora UNESP, 2004. 
Para uma sociologia da ciência. Lisboa: Edições 70, 2008.

BRASIL. Decreto ${ }^{\circ} 29.433$, de 4 de abril de 1951. Aprova o Regulamento do Conselho Nacional de Pesquisas. Disponível em: <http://www.planalto.gov.br/ccivil_03/decreto/19501969/D29433.htm> Acesso em: 15 jun. 2016. 1951.

. BRASIL, Portaria $\mathrm{n}^{\circ} 816$, de 17 de dezembro de 2002. Regimento Interno do Conselho Nacional de Desenvolvimento Científico e Tecnológico - CNPq. Disponível em: <http://cnpq.br/regimento-interno-po-816/> Acesso em: 18 jun. 2016. 2002.

CAMPANARIO, J. El sistema de revisión por expertos (peer review): muchos problemas y pocas soluciones. Esp. Doc. Cient., n. 25, p. 267-285, 2002.

CASTRO, C.; SOARES, G. As avaliações da Capes. In: SCHWARTZMAN, S.; CASTRO, C. Pesquisa universitária em questão. Campinas: Ed. da UNICAMP/Ícone Editora, 1986.

CENTRO DE MEMÓRIA DO CNPQ. Fomento e Bolsas. Disponível em: <http://centrodememoria.cnpq.br/Fombols.html> Acesso em: 07 nov. 2017. S/D.

CONSELHO NACIONAL DE DESENVOLVIMENTO CIENTÍFICO E TECNOLÓGICO (CNPq). Resolução Normativa 04/75. Consultoria Científica. Arquivo do Setor de Normas CNPq, 1975.

Resolução Normativa 01/76. Comitês Assessores (Especializados em Áreas do Conhecimento). Arquivo do Setor de Normas CNPq, 1976.

Resolução Normativa 012/88. Consultores "Ad Hoc". Disponível em:

<http://intranet.cnpq.br/normas/revogadas/normas-rn/rn-012-88.htm> Acesso em: 15 jun. 2016. 1988.

Resolução Normativa 004/98. Corpo de Assessores e Comitês de Assessoramento Normas de funcionamento. Disponível em:

<http://intranet.cnpq.br/normas/revogadas/normas-rn/rn-004-98.htm> Acesso em: 15 jun. 2016. 1998.

Resolução Normativa 014/2003. Comitês de Assessoramento - CAs, Comitês Temáticos - CTs e Consultoria Ad Hoc. Disponível em: $<$ http://intranet.cnpq.br/normas/revogadas/normas-rn/rn-014-03.htm> Acesso em: 08 jun. 2016. 2003.

. Resolução Normativa 017/2005. Comitês de Assessoramento, Comitês Temáticos, Núcleo de Assessores em Tecnologia e Inovação e Consultoria Ad Hoc. Disponível em: $<$ http://intranet.cnpq.br/normas/revogadas/normas-rn/rn-017-05.htm> Acesso em: 08 jun. 2016. 2005.

Resolução Normativa 002/2015. Comitês de Assessoramento, Comitês Temáticos, Núcleos de Assessores em Tecnologia e Inovação, Núcleo de Assessores para Cooperação Internacional e Consultoria Ad Hoc. Disponível em: <http://www.cnpq.br/web/guest/view/- 
/journal_content/56_INSTANCE_0oED/10157/2409490?COMPANY_ID=10132> Acesso em: 08 jun. 2016. 2015 a.

Resolução Normativa 028/2015. Bolsas Individuais no País. Disponível em:

<http://www.cnpq.br/web/guest/view/-

/journal_content/56_INSTANCE_0oED/10157/2958271?COMPANY_ID=10132> Acesso em 01 jun. 2016. 2015b.

A criação. Disponível em: <http://cnpq.br/a-criacao> Acesso em 12 nov. 2017. S/D.

DAGNINO, R. A comunidade de pesquisa e a política de ciência e tecnologia: olhando para os países avançados. Rev. iberoam. cienc. tecnol. soc., Ciudad Autónoma de Buenos Aires , v. 3, n. 7, p. 43-58, set. 2006. Disponível em

<http://www.scielo.org.ar/scielo.php?script=sci_arttext\&pid=S1850-

00132006000100003\&lng=es\&nrm=iso> Acesso em 19 abr. 2016.

DAVYT, A. e VELHO, L. A avaliação da ciência e a revisão por pares: passado e presente. Como será o futuro? História, Ciências, Saúde - Manguinhos, VII(1), 93-116, mar.-jun. 2000.

FONSECA, M. L. M. da. A institucionalização da pesquisa científica brasileira: os primeiros anos de atuação do Conselho Nacional de Pesquisas (CNPq). Parc. Estrat. Ed. Esp. Brasília, v. 18 , n. 36 p. 253-268, jan.-jun. 2013.

HARDING, E. Peer Review. Postnote, n. 182, set. 2002. Disponível em: <http://www.europarl.europa.eu/stoa/webdav/shared/4_publications/postnote/postnote182_en. pdf> Acesso em 19 abr. 2016.

HOLBROOK, J. Why measure science? Science and Public Policy, 19(5): 262-6, 1992.

HONNETH, A. "Reconhecimento". Dicionário de ética e filosofia moral. São Leopoldo: Unisinos, v. 2, p. 473-478, 2003.

Luta por reconhecimento: a gramática moral dos conflitos sociais. São Paulo:

Editora 34, 2009.

KERN, V., SARAIVA, L. M. PACHECO, R. Peer Review in Education: Promoting Collaboration, Written Expression, Critical Thinking, and Professional Responsibility.

Education and Information Technologies, v. 8, n. 1, p. 37-46, 2003.

KILWEIN, J. H. Biases in medical literature. Journal of Clinical Pharmacy and Therapeutics, v. 24, n. 6, p. 393-396, 1999.

KYVIK, S.; LANGFELDT, L. Researchers as evaluators: Tasks, tensions and politics Higher Education 62(2), p. 199-212, 2011.

LEE, C. at al. Bias in peer review. J. Am. Soc. Inf. Sci., v. 64, p. 2-17, 2013.

LLOYD, M. Gender factors in reviewer recommendations publication. J Appl Behav Anal, v. 23 , p. $539-543,1990$. 
MAUSS, M. Sociologia e antropologia. São Paulo: Cosac \& Naify, 2003.

NASSI-CALÒ, L. Polêmico artigo na Science expõe fragilidades da revisão por pares em um conjunto de periódicos de acesso aberto. SciELO em Perspectiva. 2013. Disponível em: $<$ http://blog.scielo.org/blog/2013/11/05/polemico-artigo-na-science-expoe-fragilidades-darevisao-por-pares-em-um-conjunto-de-periodicos-de-acesso-aberto/> Acesso em 07 jun. 2016.

Avaliação por pares: modalidades, prós e contras. SciELO em Perspectiva, 2015. Disponível em: <https://blog.scielo.org/blog/2015/03/27/avaliacao-por-pares-modalidadespros-e-contras/> Acesso em 14 mai. 2018.

OLIVEIRA, J. J. de. Ciência, tecnologia e inovação no Brasil: poder, política e burocracia na arena decisória. Rev. Sociol. Polit., Curitiba v. 24, n. 59, p. 129-147, Set. 2016.

POLANYI, M. Personal Knowledge: Towards a Post-Critical Philosophy. Chicago: University of Chicago Press, 1974.

RIP, A. The republic of science in the 1990s. Higher Education, v. 28, n. 1, p. 3-23, 1994.

ROWLAND, F. The peer-review process. Learned Publishing, n. 15, p. 247-258, 2002.

SINGER, P. Hegel. São Paulo: Loyola, 2003.

SPINAK, E. A principio era os plágios, agora também 'papers' automáticos falsos. SciELO em Perspectiva. 2014. Disponível em: <http://blog.scielo.org/blog/2014/03/31/a-principioera-os-plagios-agora-tambem-papers-automaticos-falsos/> Acesso em 07 jun. 2016

TRIGGLE, C.; TRIGGLE, D. What is the future of peer review? Why is there fraud in science? Is plagiarism out of control? Why do scientists do bad things? Is it all a case of: "All that is necessary for the triumph of evil is that good men do nothing?" Vascular Health and Risk Management, v. 3, n. 1, p. 39-53. 2007.

TRZESNIAK, P., KOLLER, S. Redação Científica Apresentada por Editores. In: SABADINI, A.; SAMPAIO, M.; KOLLER, S. Publicar em psicologia: um enfoque para a revista. São Paulo: Associação Brasileira de Editores Científicos de Psicologia/Instituto de Psicologia da Universidade de São Paulo. 2009, p. 91.

VELHO, L. A ciência e seu público. Transinformação, v. 9, n. 3, set./dez. 1997. Disponível em: <http://www.puccamp.br/ biblio/transinformação/old/vol9n3/pag15.html> Acesso em 12 Jun 2016.

WAINER, J.; VIEIRA, P. Avaliação de bolsas de produtividade em pesquisa do CNpq e medidas bibliométricas. Perspectivas em Ciências da Informação, 18 (2), p. 60 - 78, 2013. 